\title{
单斜铜泡石 $\{001\}$ 解理面的 AFM 图象*
}

\author{
廖立兵 马哲生·施倪承 \\ (中国地质大学材料科学系, 北京 100083)
}

\section{关键词单斜铜泡石 原子力显微镜(AFM) 调幅结构}

单斜铜泡石是马哲生等 1980 年发现的一种新矿物 ${ }^{[1]}$, 成分与铜泡石相似, 均为含水的砷酸 盐, 晶体化学式为: $\mathrm{Cu}_{9} \mathrm{Ca}_{2}\left[(\mathrm{As}, \mathrm{S}) \mathrm{O}_{4}\right](\mathrm{OH}, \mathrm{O})_{10} \cdot 10 \mathrm{H}_{2} \mathrm{O}$. 由于发育 $\{001\}$ 极完全解理, 适合于 进行 $\mathrm{X}$ 射线单晶结构分析的样品极难获得, 以至于该矿物晶体结构和铜泡石一样至今未知. 原子力显微镜能在正空间直接观察样品表面原子分布, 因此作者用原子力显微镜对单斜铜泡 石的表面进行了观察.

\section{1 样品与实验}

样品采自云南东川铜矿氧化带, 片状、翠绿色, 发育 $\{001\}$ 完全解理. Weissenberg 照像研 究认为该样品为单斜晶系, 可能的空间群为 $P 2 / a$ 和 $P a$, 晶胞参数为 $a=1.0513 \mathrm{~nm}$, $b=0.558 \mathrm{~nm}, c=2.761 \mathrm{~nm}, \beta=94.0^{\circ}$ [1].

原子力显微镜实验在中国科学院化学研究所研制的 CSTM-9000 型隧道电流型原子力显 微镜上进行. 关于 CSTM-9000 型原子力显微镜参见有关文献. 微悬臂材料采用直径为 $0.5 \mathrm{~mm}$ 的铇丝, 交流电化学方法制备 ${ }^{[2]}$. 实验首先在石墨标样表面进行, 得到原子级分辨率图象后再 换上待测样品, 在相同实验条件下扫描直至获得样品表面的原子结构图象.

\section{2 实验结果讨论}

图 1 是实验得到的单斜铜泡石 $\{001\}$ 解理面的原子结构图象. 根据实测的原子间距及 $\mathrm{X}$ 射线研究结果, 单斜铜泡石晶胞应取图 1 上的 $\mathrm{ABCD}, \mathrm{AB} \approx 0.55 \mathrm{~nm}, \mathrm{BC} \approx 1.04 \mathrm{~nm} . \mathrm{X}$ 射线 研究证实单斜铜泡石为原始格子而 $\mathrm{ABCD}$ 为带心格子. $\mathrm{ABCD}$ 中晶胞角顶和中心的原子坐 标应分别为 $O, O, Z$ 和 $1 / 2,1 / 2, Z$. 无论是 $P 2$ 还是 $P 2 / a$ 空间群, $O, O, Z$ 和 $1 / 2,1 / 2, Z$ 均分属于 两套不同的等效点系, 而且 $Z$ 只能是 $O$ 或 $1 / 2$. 因此图 1 显示的是 $O, O, O ; 1 / 2,1 / 2, O$ 或 $O, O$, $1 / 2 ; 1 / 2,1 / 2,1 / 2$ 位置上的原子, 分属两种不同的等效点系, 但原子种类无法得知. 图 2 为相同 样品表面更大扫描范围 $(15 \mathrm{~nm} \times 25 \mathrm{~nm})$ 获得的图象. 图 2 除模糊可见背底有与图 1 相同的原 子分布外还可见有更大周期的结构叠加其上, 即所谓的调幅结构现象. 图 2 显示的两组调幅 波 $\mathrm{A}$ 和 $\mathrm{B}$ 夹角约 $120^{\circ}$, 相应的调幅周期分别约为 $2.0 \mathrm{~nm}$ 和 $6.0 \mathrm{~nm}$. 根据图 2 背底原子行列 方向大致确定, $\mathrm{A}$ 和 $\mathrm{B}$ 调幅方向与单斜铜泡石 $a$ 和 $b$ 轴夹角大约分别为 $25^{\circ}$ 和 $5^{\circ}$, 因此两个 方向调幅的结果是在基本结构的基础上形成一个更大周期的结构. 这一现象与 Tao 等人于

1995-05-08 收稿, 1995-09-05 收修改稿

*30 届国际地质学大会资助项目 


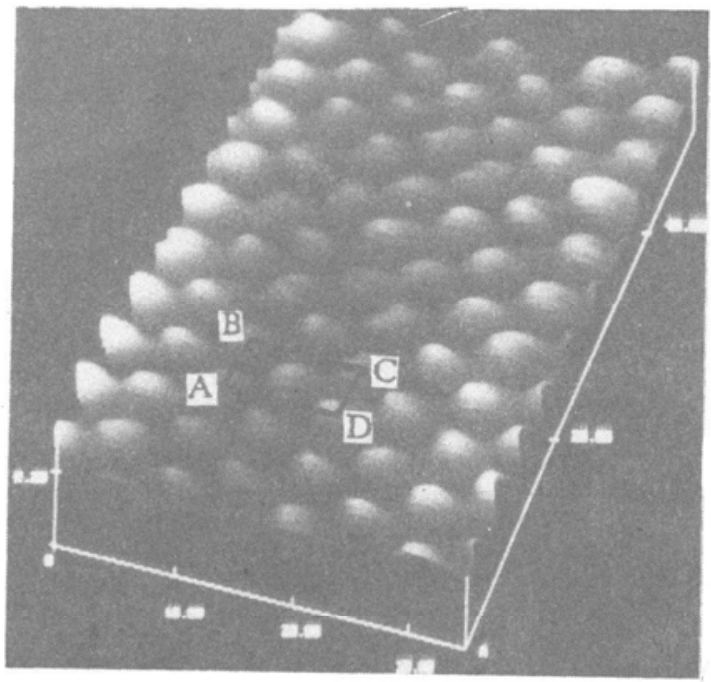

图 1 单斜铜泡石 $\{001\}$ 面的 AFM 图象 $\mathrm{ABCD}$ 为单位晶胞, $\mathrm{AB} \approx 0.55 \mathrm{~nm}, \mathrm{BC} \approx 1.04 \mathrm{~nm}$

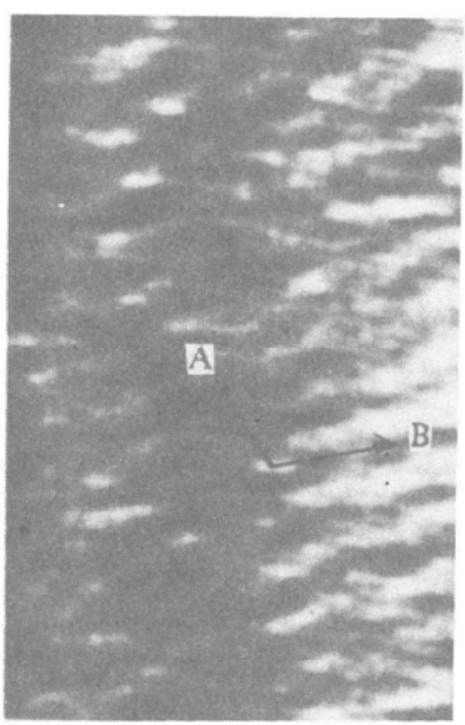

图 2 单斜铜泡石 $\{001\}$ 面的 AFM 图象 可见两个方向的调幅波 $\mathrm{A}$ 和 $\mathrm{B}$, 周期分别约为 $2 \mathrm{~nm}$ 和 $6 \mathrm{~nm}$

低温下在 $\mathrm{Bi}_{2} \mathrm{Sr}_{2} \mathrm{CaCu}_{20}$ 超导体表面用 STM 观察到的现象相似, 是一种双向面外 (out-of-plane) 调幅结构 ${ }^{[3]}$. 图 2 显示的单斜铜泡石 $\{001\}$ 面存在调幅周期分别约为 $2 \mathrm{~nm}$ 和 $6 \mathrm{~nm}$ 的调幅结构, 以及调幅方向与单斜铜泡石 $a$ 和 $b$ 晶轴不一致的现象, 由于缺乏单斜铜 泡石的晶体结构资料, 其成因尚无法解释.

\section{3 小结}

本文用原子力显微镜观察到了单斜铜泡石 $\{001\}$ 面的原子分布和两个方向的面外调幅结 构现象, 初步确定了调幅方向和调幅周期. 但由于单斜铜泡石的晶体结构未知, 以上调幅结 构的成因还无法解释.

\section{参 考 文 献}

1 马哲生, 钱荣耀, 彭志忠. 单斜铜泡石一云南东川发现的一种含水的铜的砷酸盐新矿物. 地质学报, 1980, (2): $134 \sim 143$

2 廖立兵, 马哲生, 施倪承. 用交流电化学腐蚀法制备隧道电流型原子力显微镜微悬臂. 分析仪器, 1994, (4): $31 \sim 34$.

3 Tao H J, Yin B, Yang Q S et al. Two-dimensional structure modulation in Bi-O surface layer of cleaved $\mathrm{Bi}_{2} \mathrm{Sr}_{2} \mathrm{CaCu}_{2} \mathrm{O}_{\delta+6}$ superconducting state. Model Physics Letters B, 1993, 20(7): $1313 \sim 1320$ 